\title{
Why don't adolescents eat fish? Factors influencing fish consumption in school
}

\author{
Hillevi Prell, Christina Berg and Lena Jonsson
}

Department of Home Economics, Göteborg University, Göteborg, Sweden

\begin{abstract}
Background: Theory-based research is needed to promote healthy eating in adolescents and to work out interventions.

Objective: To examine what factors influence adolescents' fish consumption in school.

Design: A total of 162 pupils from the 8th grade (age $\sim 14$ years) at two schools completed a questionnaire based on the Theory of Planned Behaviour. In 150 of these subjects, fish consumption was assessed by observation on four occasions.

Results: Attitudes towards the fish, friends' behaviour and perceived control were important predictors of the intention to eat fish. Barriers for fish consumption were a negative attitude towards both the smell and the accompaniments, and fear of finding bones. It may not be surprising that eaters of fish were more satisfied with the taste, texture and appearance of the fish and rated satiety significantly higher than resisters. They also thought to a greater extent that the fish was healthy and prepared with care.

Conclusions: The results suggest that it is important to alter dishes so that they appeal to children and to pay attention to the whole meal, accompaniments included. Finally, it may be of great importance to convey to the pupils that the fish served is healthy and prepared with care.
\end{abstract}

Keywords: Children, dietary assessment, food habits, home economics, school canteen, theory of planned behaviour.

Received: 30 October 2002; Accepted: II November 2002

\section{Introduction}

In the Swedish National Aims and Strategies for Nutrition 1999-2004, there is a recommendation that the intake of fish should increase (1). Fish has always been an important part of Swedish cuisine and an increased interest in healthy eating makes fish, which has a great deal of nutritional benefits, particularly interesting. Dietary surveys of Swedish adolescents reveal that the average intake of vitamin D, selenium, zinc and iron is below the Swedish Nutrition Recommendations (2, 3), and that the relative intake of saturated fat is high (2). Fish can be a valuable source of vitamin $D$ and selenium and contributes to the intake of iron and zinc. Fish also contains a large amount of polyunsaturated fatty acids, which can help to improve the quality of fat in the diet. Moreover, fish could be an alternative for those who refrain from eating meat for ethical reasons. Thus, fish could become an even more important source of nutrition in the future. Despite all the advantages of fish consump- tion, it seems as if especially young people have negative attitudes towards fish $(4,5)$ and schoolchildren in Sweden seem to have the lowest consumption of all age groups (6). Why is it that young people seldom like fish? More research is needed on the factors influencing food choice in adolescents.

The Theory of Planned Behaviour (TPB) (7) has been widely used to investigate factors influencing various health behaviours such as smoking, alcohol consumption, exercise and dietary behaviour. Much research has been carried out to examine food choices from a health perspective using this model, among both adults (8) and adolescents (912). The TPB postulates that behaviour can be predicted from behavioural intention and perceived behavioural control (if perceived behavioural control reflects actual control). Furthermore, an individual's behavioural intention depends on the attitude towards performing the behaviour, the subjective norm (perception of what other people 
think about the respondent performing the behaviour) and the perceived control over the behaviour. In turn, attitudes, norms and perceived control are determined by underlying beliefs and evaluations. Modifications to the model have been made. In addition to the subjective norm, a descriptive norm (the perception of how other people behave) has been successfully added $(9,11)$.

To find relations between consumption and influencing factors, it is important to focus on specific foods in specific situations in a particular age group. Therefore, this study focused on fish at school lunch. All children of compulsory school age are entitled to free school lunches in Sweden, which makes the school canteen a suitable context for studies orientated towards children's eating habits. In the present study, the aim was to examine the consumption of fish in school and the influencing factors. The study precedes an intervention study, aiming at increasing pupils' fish consumption in school; therefore, practical implications for interventions also will be discussed.

\section{Subjects and methods}

\section{Subjects and procedure}

Pupils $(n=167)$ from six 8th grade classes (age around 14 years) at two comprehensive schools situated in the Göteborg area in Sweden were invited to take part in the study. Both schools had a low share of immigrants $(<10 \%)$. The pupils were asked to complete a questionnaire that was based on the TPB and participate in an observation of their consumption of the school lunch. The week before the questionnaires were handed out, the pupils were informed by the first author about the study and its procedures and that participation was voluntary. The questionnaires were distributed during school hours under supervision of a teacher and the first author and took about 15-25 minutes to complete. In total, 162 pupils (97\%) completed the questionnaire. Three pupils declined to participate, one pupil was absent and one pupil was excluded from the study because of incomplete responses. In total, 150 pupils $(90 \% ; 80$ girls and 70 boys) underwent dietary assessment (i.e. completed all parts of the study). The dietary assessment started 1 week after the questionnaires had been distributed. The participants' intake of fish was assessed four times when fish meals were served in the school canteen (once a week). Pupils were excluded from the dietary study if they were missing (i.e. reported ill or if data on either portion taken or leftovers were missing) on two or more of the four times when the assessments took place.

\section{Questionnaire}

Before constructing the questionnaire, focus group interviews were conducted in an 8th grade class (this school was not included in the present study). The aim was to elicit salient beliefs related to the target behaviour (eating fish for school lunch). The focus group procedure and results are described more in detail elsewhere (13).

The TPB items measured intention, attitudes, subjective norm (significant others' opinion) and descriptive norm (perception of friends' behaviour), perceived control and underlying beliefs and evaluations (Table 1). In addition, the questionnaire contained a question about how often the pupils went to the school canteen in general, questions about attitudes towards fish in general and questions about fish consumption at home.

Test-retest reliability was assessed by Spearman rank correlation with an interval of 1 week with all pupils. The questionnaire was completed twice by $147(91 \%)$ of the participants. For intention, attitude, subjective and descriptive norms and perceived control, the correlation between the two occasions varied between 0.54 and 0.87 . For behavioural beliefs and evaluations, correlation varied between 0.54 and 0.78 and for control beliefs 0.50 and 0.80 .

\section{O bservation of fish consumption}

Actual behaviour (consumption of fish) was measured individually by structured observations in the school canteen setting. One person observed the taken fish component on each pupil's plate and another person the leftovers. The size of a portion was determined on the basis of normal portions (14). Each observer had plates with weighed portion sizes to compare visually with the portion size on the pupils' plates. The observations aimed to categorize the pupils into non-eaters, tasters and eaters of fish. Participants who had eaten more than half a portion on at least two of the four measurement occasions were categorized as eaters. All those who had taken fish at least once at the four lunches were categorized as tasters.

Before conducting the consumption study, interobserver agreement was tested for 100 test portions. Two kinds of fish meal in three portion sizes were assessed. Observed portion size was compared with actual weight, and the individual assessments 
Table I. Wording of the Theory of Planned Behaviour variables and response scales

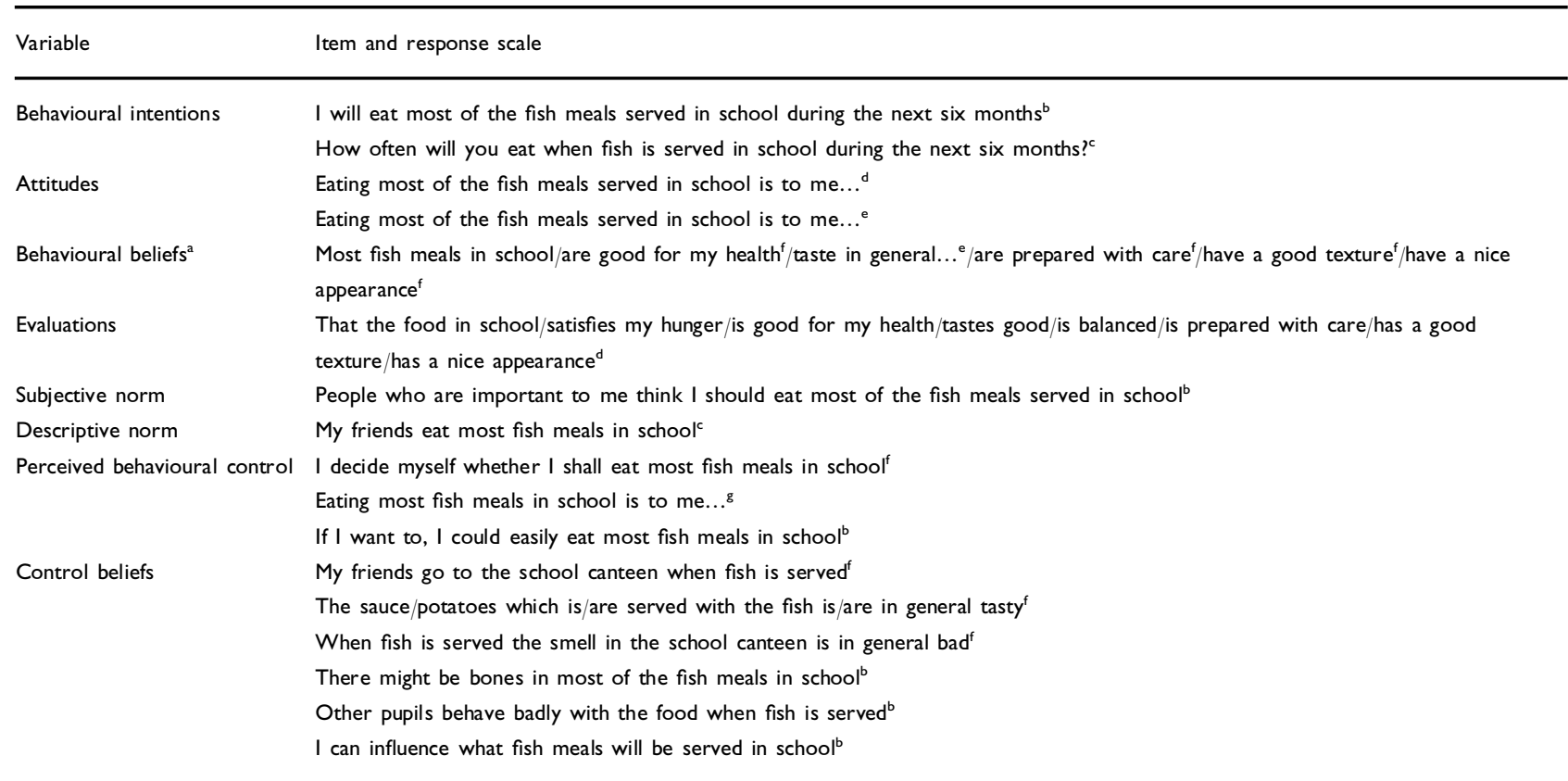

\footnotetext{
${ }^{a}$ Two behavioural belief items (about satiety and balanced diet) were excluded because pupils who do not eat fish in the school canteen might misunderstand them.

${ }^{b}$ Definitely no-Probably no-Maybe no-Don't know-Maybe yes-Probably yes-Definitely yes.

'Never-Very seldom-Seldom-Half of the time-Often-Very often-Always.

${ }^{d}$ Not important at all-Not important-Not particularly important-Neither-Rather important-Important-Very important.

e Very bad-Bad-Rather bad-Neither-Rather good-Good-Very good.

' Definitely disagree-Disagree-Maybe disagree-Don't know-Maybe agree-Agree-Definitely agree.

\& Very easy-Easy-Rather easy-Don't know-Rather difficult-Difficult-Very difficult.
}

of the two observers (the first author and an assistant) were compared with each other. Percentage agreement for observed portion size compared with the weighed portions was $84 \%$ and interobserver agreement was $80 \%$.

\section{Statistical analysis}

Non-parametric statistics were used since the data were considered to be on an ordinal level scale. The associations between the variables in the model were examined by Spearman rank correlation coefficients. Internal consistency for the variables assessed by two items were $r_{\mathrm{s}}=0.90$ for behavioural intentions, $r_{\mathrm{s}}=0.72$ for attitudes and $r_{\mathrm{s}}=0.04-$ 0.55 for the three perceived control items. One of the items measuring perceived control, "I decide myself whether I shall eat most fish meals in school", was excluded from the analysis owing to a weak association with remaining control items $\left(r_{\mathrm{s}}=0.04-0.08\right)$. The pupils said that they did not understand the question and their responses were unevenly distributed (97\% of respondents agreed with the statement).
The prediction of consumption of fish in school on the basis of the independent variables intention and perceived control was tested in a logistic regression model. The prediction of the intention to eat fish by the original variables of the TPB (attitude, subjective norm and perceived control) together with descriptive norm was also investigated. The variables were dichotomized for these analyses. The scales were scored as 1 for positive categories and 0 for indifferent and negative alternatives, and when reflecting frequency, 0 for very seldom and never. The two items for each of intention, attitudes and perceived control were combined into one item in the logistic regression models (e.g. intention $=1$, if either the first intention item or the second or both $=1$ ). Behaviour was categorized into resisters (non-eaters and tasters) and eaters. Non-significant variables were excluded stepwise so that only significant variables remained in the final model. Similarly, logistic regression was performed for the prediction of beliefs on the basis of attitude towards the fish in school for those with a positive attitude towards fish in general. Box plots were used for between-group 
comparisons of the distribution of values. Resisters and eaters were compared with respect to behavioural beliefs, evaluations and control beliefs. Differences in responses between groups were assessed using the Mann-Whitney test. All the analyses were carried out using the statistical package SPSS 10.01999.

\section{Results}

\section{Fish consumption}

Approximately half of the pupils (54\%) claimed that they always had the lunch served in school, while $6 \%$ seldom or never had school lunch. According to the observations of fish consumption, $53 \%$ were categorized as fish eaters and $35 \%$ as tasters, and $15 \%$ did not eat or take the fish in the school canteen. Regarding fish consumption in general, only $3 \%$ claimed that they never had any fish at all. Of those, two were vegetarians and the remaining two pupils did not like fish.

\section{Predicting consumption and intention to consume}

Behaviour (consumption of fish in school) was associated with both intention and perceived control. Spearman rank correlation with behaviour was 0.66 and 0.68 for the intention items and 0.60 and 0.36 for the perceived control items. For the two behavioural intention items, the strongest correlation was with attitudes $(0.63-0.64)$ and the perceived control items (0.42-0.69). Remaining correlations with intention were 0.42 and 0.46 for descriptive norm and 0.32 and 0.36 for subjective norm. All correlations were significant $(p<0.001)$.

In agreement with these findings, logistic regres- sion analyses showed that consumption of fish in school could to a great extent be predicted from the children's intention to eat the fish served and whether they perceived that they had control over the consumption (Fig. 1). Intention to eat the fish was in turn explained by the pupils' attitude towards the fish served in school, their perceived control over the consumption, and their friends' practices regarding fish in school (descriptive norm). Their attitude towards consumption was the strongest predictor of the intention. The opinion of people who were important to the pupil (subjective norm) did not contribute significantly to the model.

\section{Beliefs and evaluations}

Because attitude was a significant predictor of intention, underlying behavioural beliefs and evaluations were examined further. Resisters' beliefs about the fish served in school were in general more negative than those of the eaters (Fig. 2). The differences were significant for all beliefs. In other words, eaters were more likely to believe that the fish was healthy and prepared with care than were resisters. They also liked the taste, appearance and texture better than resisters.

Group differences were also examined regarding evaluation of outcomes (health, taste, prepared with care, texture, appearance, satiety and balanced diet). There were no significant differences between eaters and resisters, except for the evaluation of satiety. The great majority of the participants $(91 \%)$ reported that it was important that the lunch in school satisfied their hunger; nevertheless,

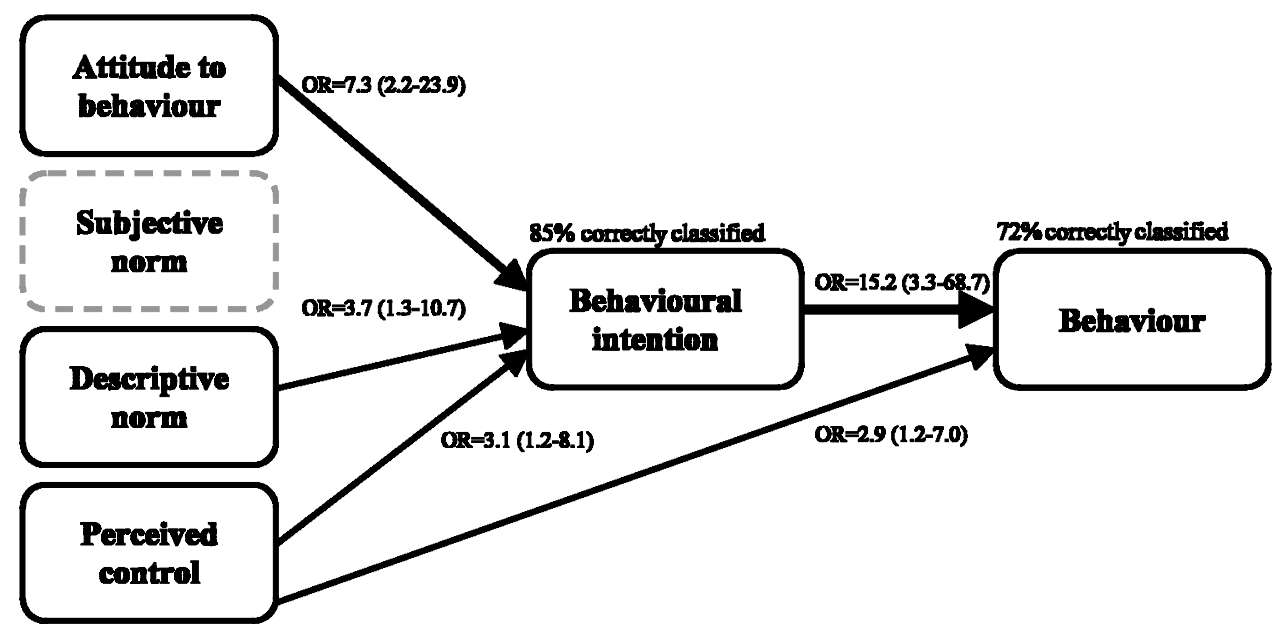

Fig. 1. Results of logistic regression analysis predicting behaviour and intentions to eat fish in the school canteen. Final model with odds ratio (OR and 95\% confidence interval in parentheses) for significant variables and per cent correctly classified by the model. 


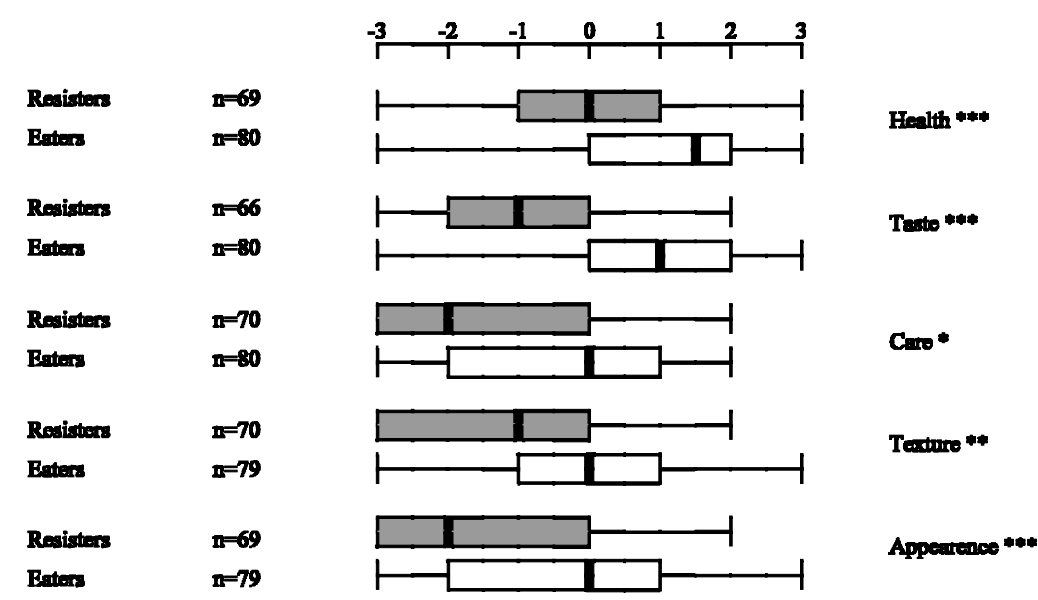

Fig. 2. Beliefs about eating fish in the school canteen: responses of resisters and eaters. Response categories for taste: $-3=$ very bad; -2 = bad; $-1=$ rather bad; $0=$ neither; $1=$ rather good; $2=$ good; $3=$ very good. Response categories for remaining beliefs: $-3=$ definitely disagree; $-2=$ disagree; $-1=$ maybe disagree; $0=$ don't know; $1=$ maybe agree; $2=$ agree; $3=$ definitely agree. The box plot shows the median (thick line), quartiles (the length of the box) and the 2.5 and 97.5 percentiles. Mann-Whitney test: $* p<0.05, * * p<0.01$, $* * * p<0.001$.

eaters rated satiety significantly higher than resisters $(p<0.01)$.

Further analyses of control beliefs showed significant differences between resisters and eaters regarding factors facilitating and inhibiting consumption (Fig. 3). Resisters were more likely to think that the smell in the school canteen was bad when fish was served and they seemed to be more convinced that the fish would contain bones. Furthermore, they were less satisfied with the taste of the sauce. No corresponding association was observed for perceptions of the taste of the potatoes served with the fish, but in general the pupils were not pleased with the potatoes. Likewise, a large proportion of the pupils $(55 \%)$ did not think that they had the possibility of influencing what fish meals were going to be served for school lunch. Friends not going to the school canteen and other pupils behaving badly with the food did not seem to be among the most important control factors.

Why do some like fish at home but not in school? A large proportion of the pupils (73\%) claimed that they had a positive attitude towards fish in general,

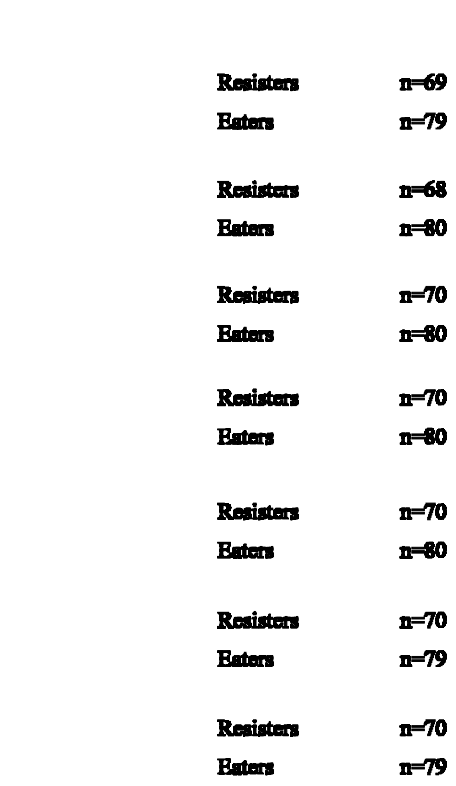
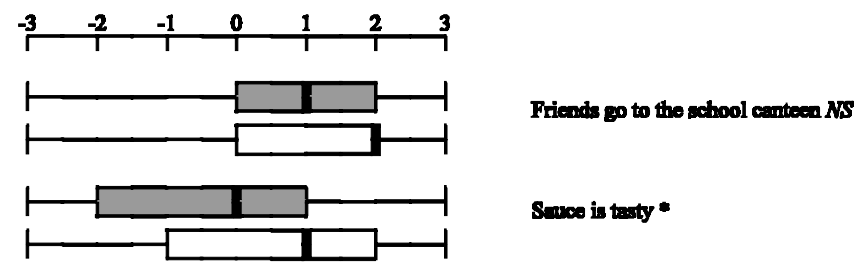

Souce is tasty *

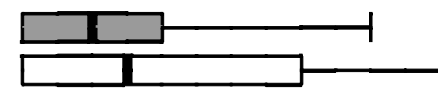

Potatoes aro tasty NS

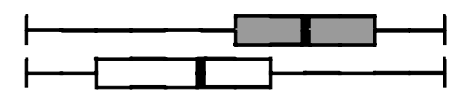

Smell is bedm*t

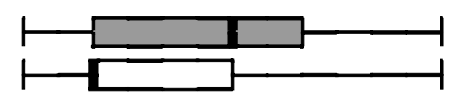

Bomes *t*

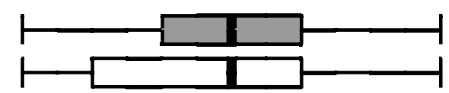

Other pupila behavo badly $N S$

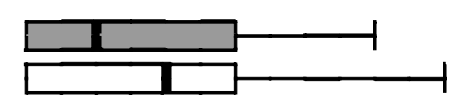

Influence $N S$

Fig. 3. Control beliefs about eating fish in the school canteen: responses of resisters and eaters. Response categories for bones, other pupils behaving badly and possibility of influencing the menu: $-3=$ definitely no; $-2=$ no probably not; $-1=$ no maybe not; $0=$ don't know; $1=$ yes maybe; $2=$ yes probably; $3=$ definitely yes. Response categories for remaining control beliefs: $-3=$ definitely disagree; $-2=$ disagree; $-1=$ maybe disagree; $0=$ don't know; $1=$ maybe agree; $2=$ definitely agree; $3=$ agree. The box plot shows the median (thick line), quartiles (the length of the box) and the 2.5 and 97.5 percentiles. Mann-Whitney test: $* p<0.05$, $* * * p<0.001$; NS: non-significant. 


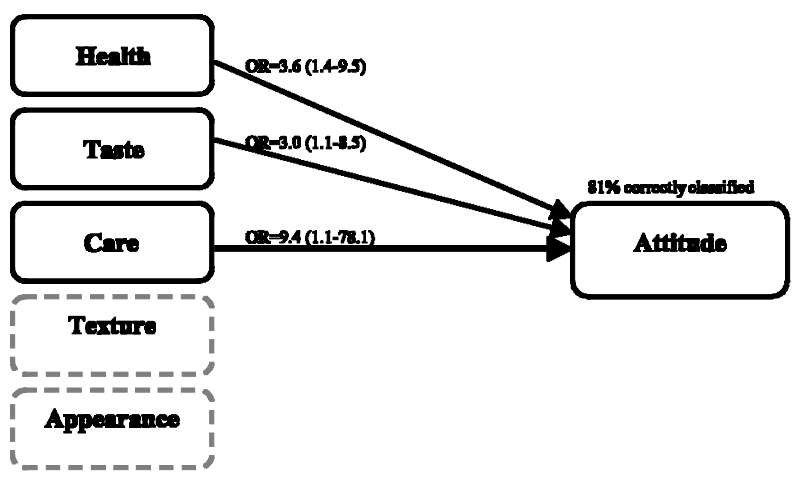

Fig. 4. Results of logistic regression analysis of beliefs predicting the attitude towards eating fish in the school canteen. Only those with a positive attitude towards fish in general are included $(n=$ 118). Final model with odds ratio (OR and $95 \%$ confidence interval in parentheses) for significant variables and per cent correctly classified by the model.

but only $55 \%$ were positive towards fish in school. This negative attitude also seemed to be reflected in consumption. Among those eating fish at home often, at least twice a week, more than one-third were categorized as resisters (i.e. did not eat the fish in school or only tasted). To focus on what the pupils do not like in connection with eating fish in school, those 118 pupils who were positive towards fish in general were analysed further. Their attitudes towards the fish in school were examined in a logistic regression model with beliefs about health, taste, care, texture and appearance as independent variables (Fig. 4). Attitudes towards the fish in school were significantly predicted by beliefs about whether the fish served was healthy and tasty, and whether it was prepared with care.

\section{Discussion}

\section{O bservation of fish consumption}

One of the advantages of this research was that actual behaviour (fish consumption) was assessed objectively by structured observations in the school canteen. Few studies assess actual intake objectively. In most TPB studies, behaviour is assessed by self-report. A benefit of using observation as a method is that the behaviour is studied in its natural context at the same time as it occurs. Consequently, the method is not dependent on people's memory and is relatively independent of their willingness to give information. However, food intake is closely linked to personal integrity and one's sense of self (15). The act of observing and recording what people intend to put into their mouths could make them feel uneasy and influence them to alter their behaviour. Thus, when carrying out dietary assessment by observation, it can be difficult to assess whether the observed behaviour is representative and spontaneous. The fact that two observers were present and made notes of the pupils' in take might have influenced the children to take at least a small amount of fish even if they had had no intention of doing so at that particular meal. To evaluate how the pupils experienced the observation, group interviews were conducted. These were held with three groups of eight to 10 pupils each after the four observations were completed. All pupils claimed that they behaved as they usually did and assured that the observations did not make them feel uneasy.

Since this study was not interested in deciding exact fish intake, the authors believe that the observations served their purpose by giving a rough measure for dividing the pupils into non-eaters, tasters and eaters of fish. The weighing method is much more exact than carrying out observations. However, assessing dietary intake by weighing would be quite difficult in a school meal situation with pupils impatiently waiting to take food, and would probably have influenced their behaviour more. Measuring fish consumption only four times, as was done in this study, may be insufficient since the whole range of fish dishes usually served at both schools did not appear on those occasions. Only one dish at a time was served for lunch in the schools where the study was carried out. Nevertheless, both fried and cooked fish as well as fish au gratin were represented on at least one of the four occasions in the two schools, and the goal was not to determine differences in consumption between the various fish dishes.

\section{Influences on fish consumption in school}

With $72 \%$ of the actual behaviour and $85 \%$ of the intention predicted, the findings corroborate the efficiency of the TPB model in explaining the determinants of adolescents' fish consumption in school (Fig. 1). Attitudes towards consumption appear to play a large part in influencing intention, and thus consumption. This is in line with other studies using the TPB model to predict consumption of fish (16), as well as other foods $(9,11)$.

In addition, social factors were associated with the intention to eat fish in school. Consistent with other TPB studies of adolescents' food choice (9, 11), friends' behaviour (descriptive norm) contributed to predicting the intention. However, children's perceptions of opinions of people who are 
important to them did not add significantly to the model. Hence, the results suggest that the behaviour of friends had an impact on the pupils' consumption of fish in school. However, since usually only one dish is served within the school meal context, as was the case in the present study, one may expect a resemblance between the foods consumed by friends. In addition, since this study dealt with eating away from home, a smaller parental influence would be expected. Eaters of fish in school considered satiety to be very important and, indeed, this may be the principal goal for pupils eating in the school canteen. In a food culture which is primarily determined by a restricted choice, hedonic factors may be of less importance. However, it is not only satiety that separates fish eaters from resisters. Eaters liked the taste of the fish better and they were more satisfied with the appearance and texture of the fish meals and the sauce. They did not think that the fish contained bones or that the smell was unpleasant to the same extent as resisters. Nevertheless, to encourage more pupils to eat the fish in school it might not be enough to change the preparation of the fish or the menu; it may also be important to convey that the fish is healthy and prepared with care.

The school canteen environment itself may have a strong impact on eating behaviour and attitudes towards the served fish meals. Previous studies have shown that the school food service offers a context in which the food was least accepted (17) and that the attitude towards eating various food items in the school canteen was more negative than eating at home or in a restaurant (18). As Mennel et al. (19) point out, "Institutions constitute an intriguing type of social arena in which food preparation and consumption take place. On the one hand, they are settings, which stand in contrast to the public commercialized world of eating out. On the other, they stand in contrast to home cooking in the household domain of the personal, private and intimate. At the same time, institutions are to stand in for the domestic sphere, at least in some measure" (p. 112).

The actual school food service environment and the difficulty of influencing what meals are going to be served are some important features that may have a negative impact on consumption. It also seems as though the pupils found it difficult to perceive that the fish is prepared with care. This is perhaps a major issue that separates institutions such as the school food service from the home.
The analysis of the attitude towards the fish in school among those with a positive attitude towards fish in general supports this hypothesis. This was also one of the findings of the pilot study with focus group discussions in which the pupils referred to the way their mothers prepared the fish at home as being much better than in school (13).

\section{Practical implications for interventions}

The results of this study have practical implications for the design of interventions aiming at increasing fish consumption in school. Such interventions should address change at both the individual and the organizational level. Both home economics classes and the school canteen should be involved in this process, and both attitudes and control should be intervention targets.

The Swedish school meal constitutes a unique possibility to offer and market varied and nutritious food. The importance of the school food service staff must be stressed. They are vital in that they prepare the food and market it. They need to register the opinions of the pupils and be sensitive and open to their suggestions. What does care mean for them and how could it be expressed in a school meal context? There is no simple answer. The opinions of the staff could be investigated more thoroughly to obtain their view of the school meal situation and how it could be changed. It is important that the food service staff pay attention to the whole meal, including accompaniments such as sauce and potatoes. In addition, pupils should have the chance to influence what fish meals are served in school. The choice of fish meals needs to be extended and preferably pupils should have two kinds of dish from which to choose, in order to favour consumption. This is recommended in the newly published guidelines for school lunches (20).

Home economics classes represent an excellent opportunity for tasting and acquainting oneself with fish, as well as for communicating knowledge about the health aspects of fish consumption. Resisters need help to overcome any uncomfortable feelings towards the bones in the fish and the smell. This could be achieved by direct experience such as practising cooking and eating with peers. The present study suggests that friends' behaviour (descriptive norm) is important for the intention to eat fish in school. Eating with peers with a positive attitude towards fish in school may therefore influence those with a less positive attitude. Co-operation between the home economics 
classes and the school lunch service should be encouraged so that, for instance, the pupils prepare the same types of dish that are served in the school canteen. The home economics teacher could show (perhaps with slides) the way in which the school food service staff prepare the fish and the children could be given the opportunity to experience some work in the school lunch kitchen. In this way, they may notice that the fish is prepared with the same care as at home.

In conclusion, what will make pupils eat fish in school? In addition to having a positive attitude towards eating fish, it is important that their friends also eat fish and that they feel that they have control over the consumption. To encourage the children to eat fish, it is essential that the meal is prepared so that, as far as possible, they consider it to have a nice taste, smell and appearance. It is also important that the pupils like the accompaniments and that they are not afraid of finding bones in the fish. Furthermore, for pupils to like the fish, it is important that they perceive that it is healthy and prepared with care. To achieve this the opinions of the pupils must be sought and the menu changed accordingly; in addition, attitudes may be influenced through marketing and information provision.

\section{Acknowledgements}

We would like to thank Professor Tommy Gärling and Professor Lauren Lissner for scientific advice. We would also like to thank Kerstin Bergström for her contribution to the dietary assessment. The work was supported by a grant from K LIV (Kunskapsplattform för livsmedelsbranschen, Marknadstekniskt centrum).

\section{References}

1. Livsmedelsverket, Folkhälsoinstitutet. Nationella mâl och strategier för nutrition 1999-2004. [National goals and strategies for nutrition 1999-2004]. 1999.

2. Bergström E, Hernell O, Persson L. Dietary changes in Swedish adolescents Acta Paediatr 1993; 82: 472-80.

3. Samuelson G, Bratteby LE, Enghardt H, Hedgren M. Food habits and energy and nutrient intake in Swedish adolescents approaching the year 2002. Acta Paediatr Suppl 1996; 415: 1-19.

4. Norström K, Otterskog L. Attitydundersökning om fisk och skaldjur. [Attitude survey of fish and shellfish]. SCB: Stockholm: 1997.

5. Pettersson A. Allmänhetens inställning till fisk och skaldjur. [Public opinions of fish and shellfish]. SIFO: Stockholm; 1995.

6. Becker W. Befolkningens kostvanor och näringsintag i Sverige 1989. Metod och resultatanalys. [Food habits and nutrient intake in Sweden 1989. Method and results]. Uppsala. Livsmedelsverkets förlag; 1994.

7. Ajzen I. The theory of planned behavior. Organ Behav Hum Decis Process 1991; 50: 179-211.

8. Conner MT, Sparks P. The theory of planned behaviour and health behaviours. In: Conner MT, Norman P (eds). Milton Keynes. Predicting health behaviour. Open University Press: 1996: p. 121-62.

9. Berg C, Jonsson I, Conner M. Understanding choice of milk and bread for breakfast among Swedish children aged 11-15 years: an application of the theory of planned behaviour. Appetite 2000; 34: 5-19.

10. Conner M, Martin E, Silverdale N. Dieting in adolescence: an application of the theory of planned behaviour. Br J Health Psychol 1996; 1: 315-25.

11. Dennison CM, Shepherd R. Adolescent food choice: an application of the theory of planned behaviour. J Hum Nutr Diet 1995; 8: 9-23.

12. Gummeson L, Jonsson I, Conner M. Predicting intentions and behaviour of Swedish 10-16-year-olds at breakfast. Food Qual Prefer 1997; 8: 297-306.

13. Prell H. Att undersöka ungdomars attityder till skollunchen med fokusgrupper. [Using focus groups to examine adolescents' attitudes towards the school lunch]. In: Shanahan H, Ellegârd K, eds. Kreativa metoder inom konsumentforskning i empirisk belysning. Göteborg: Institutionen för hushâllsvetenskap, Göteborgs universitet; 2002. p. 91-103.

14. Livsmedelsverket. Vikttabeller för livsmedel och maträtter. [Weight tables for foodstuffs and dishes]. Uppsala: Statens Livsmedelsverk; 1992.

15. Lupton D. Food, the body, and the self. London: Sage; 1996.

16. Bredahl L, Grunert K. Determinants of the consumption of fish and shellfish in Denmark: an application of the theory of planned behaviour. Paper presented at the International Seafood Conference, Noordwijkerhout, The Netherlands, November 1995. p. 13-6.

17. Meiselman HL, Johnson JL, Reeve W, Crouch JE. Demonstrations of the influence of the eating environment on food acceptance. Appetite 2000; 35: 231-7.

18. Cardello AV, Bell R, Kramer FM. Attitudes of consumers toward military and other institutional foods. Food Qual Prefer 1996; 7: 7-20.

19. Mennel S, Murcott A, Otterloo AH. The sociology of food, eating, diet and culture. London: Sage; 1992.

20. Livsmedelsverket, Centrum för Tillämpad Näringslära/ Hälsomâlet. Riktlinjer för skolluncher - râd, tips och mängdtabeller. [Guidelines for school lunches - advice, suggestions and quantities]. Uppsala: Livsmedelsverket; 2001.

Hillevi Prell
Department of Home Economics
Göteborg University
Box 12204
SE-402 42 Göteborg
Sweden
E-mail: Hillevi.Prell@ped.gu.se

